\title{
Psychosocial aspects of the Tsunami
}

\author{
Manuel Carballo Bryan Heal Mania Hernandez
}

J R Soc Med 2005;98:396-399

Humanitarian relief has traditionally concentrated on visibly pressing issues such as the need for clean water and sanitation, emergency feeding and shelter, primary care, management of injuries and death, and the prevention of communicable diseases. Such interventions were the main focus of relief operations after the Tsunami of 26 December 2004. Since the war in the former Yugoslavia, however, there has been increasing interest in the psychosocial dynamics of both natural and man-made disasters, ${ }^{2-7}$ and in the wake of the Tsunami more than three hundred psychosocial projects of various kinds were initiated.

The way in which people will respond to a disaster cannot be predicted with precision: psychosocial outcomes are influenced by personal, social and cultural factors. Not all people will respond in the same way or even suffer from trauma as conceptualized in Western models. ${ }^{2,5}$ It is also important to keep in mind that disasters can affect people who do not experience them at first hand. ${ }^{3}$

\section{IMPACT}

Natural disasters and complex emergencies create new types of vulnerability by disorganizing families and disrupting communities, causing death and injury, and forcing people from their homes. In February of this year the World Health Organization estimated that $20-40 \%$ of the people affected by the Tsunami might suffer from shortlasting mild psychological distress. WHO also estimated that another $30-50 \%$ would experience moderate to severe psychological distress that might resolve with time, or mild distress that could become chronic. ${ }^{8}$ In June it reported that half the affected population were actually experiencing psychological problems, 5-10\% of which might require treatment. ${ }^{9}$ In the Maldives, the Ministry of Health in one of its early reports suggested that as many as 7000 people, primarily women and children, might have been traumatized by the Tsunami. ${ }^{10} \mathrm{~A}$ WHO-funded study by the University of Indonesia reported that 20-25\% of children affected by the Tsunami in Aceh required professional treatment for psychosocial problems. ${ }^{11}$ The UN Office for the Coordination of Humanitarian Affairs also reported that in January a

International Centre for Migration and Health, 11 Route du Nant d'Avril, 1214 Vernier, Switzerland

Correspondence to: Dr Manuel Carballo, Executive Director, ICMH

E-mail: mcarballo@icmh.ch quarter of children in Thailand were not attending school because of fear and distress. ${ }^{12}$ Additionally, a dramatic increase in the demand for counselling and psychological care, including tertiary-referral specialized care, was registered in the entire country. ${ }^{13}$ In Indonesia too the Tsunami precipitated a spate of referrals for psychological troubles, with a reported 15-20\% increase in outpatients with anxiety and depression. ${ }^{14} \mathrm{~A}$ corresponding increase was registered in the number of drugs prescribed for psychological distress. ${ }^{1}$ Not all these were people who had been directly affected; some were people in nearby areas who vicariously shared the trauma of the Tsunami and worried about the possibility of new waves. Previous studies in Bosnia ${ }^{3}$ have shown how the psychosocial impact spreads far beyond those who have suffered directly.

We still lack precise data on the overall nature and scope of mental health and psychosocial problems in the populations that were affected by the Tsunami. This is partly because of the special difficulties in gathering data on these matters after a disaster, but it also reflects a more complex challenge - that of formulating operational definitions of mental health and psychosocial problems that can be used across cultures and in countries where terms such as 'mental health' and 'psychological problems' are not necessarily part of the local language. Furthermore, psychosocial damage takes many forms. In some cases it is immediately obvious and demands attention; in others it easily goes unnoticed by those in a position to help. In some it is transitory and people manage to cope; in others the impact is long-term. Attitudes towards care and treatmentseeking also vary: in certain cultures an admission of the need for psychological care is stigmatizing, so that people are reluctant to seek help from professionals or even local community-based carers.

One of the new vulnerable groups created by the Tsunami were those who 'lost place'. A home, no matter how poor and substandard, can symbolize years of personal and familial investment and memories; Fullilove ${ }^{15,16}$ has described how profound and longlasting can be the psychological impact of losing 'place' or home. Thus, in depriving at least 1.2 million people in the region of place, the Tsunami created a population that six months later still has little notion of what will happen and feels increasingly powerless to control the future. These groups are in danger of becoming dependent on external assistance for survival. 
Most vulnerable are the poor, because they typically live in ill-constructed homes in areas at risk of landslides and floods, rarely have rights to the land they live on, and have little access to financial compensation or even the right of return. Their capacity for reconstruction is low because they have scant savings to fall back on and most do not know how to navigate the administrative systems that might possibly help them.

The Tsunami also affected host families and communities. In all the affected countries, extended families, friends and strangers took in displaced people and thus alleviated some of the need for special camps and centres. They provided a roof and four walls and became a major source of psychosocial support. But host families now feel they are being overlooked by many of the relief operations. They believe they are not being given a fair share of the relief goods available to displaced people, despite having sacrificed their own scarce space, privacy and materials. On the reverse side, displaced people in some of these communities are beginning to say that they are not being truly integrated and are not being allowed to participate in decision-making about their future. The reality is that the arrival of displaced people in massive numbers has become a heavy burden on households and communities for whom space, food and even mattresses were always scarce. Given that in many parts of the region these people may have to remain displaced for some time, this new tension and the collective sense of relative deprivation could become a serious issue.

Women are often thought of as a vulnerable group, and in the Tsunami women were indeed more likely to die than men; in some communities up to four times more women died. Many women were unable to swim and, for some, their traditional clothing was too cumbersome for mobility in the water. Their culturally prescribed long hair also often became entangled in tree branches. The instinctive urge of mothers to look out for the safety of their children also led many of them to return to beaches in search of children just as secondary waves came in. This high female mortality, as well as creating large numbers of widowers, has left hundreds of thousands of children motherless in settings where options for alternative care are very limited. In areas where Sharia law is practised it is uncertain what will happen to surviving widows, who are not traditionally entitled to inherit land or other possessions. Whatever the answer, the legal procedures are likely to be slow everywhere in the region, and these women may have to wait a long time for what little is coming to them. Women in disasters are also vulnerable to sexual violence. Within days of the Tsunami there were reports of surviving women being raped by other survivors and by rescuers.

Survivor guilt is a not uncommon phenomenon after disasters: 17,18 why did I survive and not my loved ones, could I have done more to help save my relatives? Such worries affect children as well as adults: in the Maldives numerous children said they felt guilty about their failure to hold younger siblings aloft in the water or to keep hold on them when the sea swept back.

Children who lost mothers or fathers or both are especially vulnerable. The social devastation in some communities has been such that other relatives are no longer present or in a position to 'adopt' orphans. Even if they were, their economic and household conditions may be too precarious to allow adequate care. In Indonesia, where at least 8316 children lost one or both parents, ${ }^{11}$ it is difficult to foresee what mechanisms can be developed, especially if children are to be allowed to stay within or return to their original communities. The number of orphaned children in India, while not as massive as in Indonesia, is nonetheless sizeable (1744), ${ }^{19}$ and in Sri Lanka the toll has likewise been very high. ${ }^{20}$ Orphanages are one option: in India, Parliament committed itself to adopting the Tsunami orphans and evacuated them to orphanages and other places of security. Orphanage care, however, is not without its critics ${ }^{20-23}$ and the implications for psychological as well as physical development will have to be considered.

What of the elderly? The psychosocial as well as the physical needs of this group have been relatively neglected ${ }^{24}$ - partly because their needs are commonly assumed to resemble those of other adults (the same applies to adolescents). Their needs are in reality often greater and more complex. For example, if they have pre-existing chronic diseases and depend on prostheses and aids to walk, see, and hear, they will be much more seriously affected by a disaster. In the Indian Ocean countries, elderly people were at particular risk of being killed by the Tsunami because they were insufficiently mobile to flee incoming waves - and probably many could not swim. The elderly people who did outsurvive younger relatives now find themselves without the social and economic support that in traditional societies comes almost exclusively from offspring and other family members. It is not yet clear how their needs will be responded to within the framework of national and international efforts.

As well as aggravating the condition of people who had disabilities beforehand, the Tsunami left many people with new physical disabilities. The need for amputations was great, some done hurriedly and without anaesthesia. ${ }^{25}$ In certain locations the demand for prostheses was such that voluntary groups were working in parallel with the formal healthcare system to fit artificial limbs. The loss of a limb is always psychologically traumatizing and calls for careful and consistent counselling; in many of the Tsunami-affected communities, healthcare services were unable to provide 
such counselling and psychosocial problems are being reported among amputees. ${ }^{1}$

From a psychosocial perspective, the tourists and their families deserve special mention. In Thailand, for example, more foreigners (1845) and people of unknown origin (1769) are known to have died than Thais (1780), and 1005 foreigners are still missing. ${ }^{26} \mathrm{~A}$ large number of the foreigners were tourists. When people were reported missing, relatives and friends flew to Thailand to assist in identification of bodies and in the recovery operation. Few were prepared for what they found and many required counselling, either while there and on return home. For those who have still not been able to secure closure - that is to say, get final confirmation that their missing relatives did die-there will probably be a continuing need for counselling.

\section{RESILIENCE}

An earlier study of Cambodian refugees made reference to the coping abilities and resilience of surviving victims, which were judged an important resource in complex emergencies. ${ }^{1,4,27}$ This observation has been supported by findings in Bosnia, Rwanda, Eritrea, and Sri Lanka where man-made disasters caused death, injury and social upheaval. $3,5,11,28,29$ In the case of the Tsunami, a seemingly important factor in natural resilience was the religious grounding of the people and the ability of local religious leaders (Aceh, Indonesia and the Maldives) to support and mobilize them to help each other. In Sri Lanka, the prevailing religious philosophy and worldview also seems to have helped people overcome their personal losses - in accordance with previous observations that religious belief can provide a basis for coping. ${ }^{30,31}$

\section{CONCLUSIONS}

As a result of the Tsunami, hundreds of thousands of people require psychosocial help in a region where the relevant specialists are few. ${ }^{24}$ The newly vulnerable groups will require much support if their predicament is not to worsen in coming months. National and international agencies must determine the ways in which local resources can be strengthened and discover which types of psychosocial intervention people in different countries find relevant and acceptable. Unless this happens, the interventions that might be imported from abroad could be wasted.

Training of local personnel should provide a basis for sustainability, but national and local agencies will need to pay attention to the social psychology of displacement and loss of place. Moreover, the affected people must be involved more closely in decision-making; at present many of them feel left out, unsure when or even whether they will ever get home.
At the same time, we should not forget that the type of support required may differ from culture to culture. In all of this, attention will have to be given to debates about the nature of 'trauma' in disasters and the type of support people need in different cultural settings, what the content of that help and care should be, and how and by whom it should be provided. $2,4,5,32$ To date, most models of psychosocial assistance have come from Western countries and are based on Western notions of trauma. ${ }^{5}$ Some of those affected by the Tsunami may react poorly to alien approaches. It would be foolish, however, to rush to the alternative judgment that people in non-Western cultures are less vulnerable to anguish and less in need of help from outside. Nor is it to say that external groups should refrain from intervening, for in many settings they may be one of the few sources of support available. Rather, it is to say that external (as well as internal) groups must always pay careful attention to local cultures, religions and traditional ways of coping with incidents such as the Tsunami. ${ }^{2-5,25,33,34}$

Finally, the likelihood of another huge tsunami may be small but the likelihood of other natural disasters occurring in the same region and elsewhere is high. One of the lessons learned thus far from the Tsunami is the importance of defining, well before disasters occur, how different cultures view them and how they are likely to respond. The psychosocial aspects of displacement, loss of loved ones, and loss of place call for more attention than they have so far been given.

Acknowledgments We thank the participants of the ICMH Tsunami Expert Review Committee meeting that took place in Male, Maldives, 22-24 April and the Taiwan International Health Operations Center and others for their support of this project.

\section{REFERENCES}

1 International Centre for Migration and Health. Interim Report of a Meeting on Public Health Impact of the Tsunami. Geneva: ICMH, April 2005

2 Almedon AM, Summerfield D. Mental well-being in settings of 'complex emergency': an overview. J Biosoc Sci 2004;36:381-8

3 Carballo M, Smajkic A, Zeric D, Dzidowska M, Gebre-Medhin J, Van Halem J. Mental health and coping in a war situation: the case of Bosnia and Herzegovina. J Biosoc Sci 2004;36:463-77

4 Mollica RF, Cui X, McInnes K, Massagli MP. Science-based policy for psychosocial interventions in refugee camps: a Cambodian example. $J$ Nerv Ment Dis 2002;190:158-66

5 Summerfield D. A critique of seven assumptions behind psychological trauma programmes in war-affected areas. Soc Sci Med 1999;48:1449-62

6 Santa BJ. The psychological effects of war on children. In: Levy BS, Sidel VW, eds. War and Public Health. Washington: APHA, 2000:168-85

7 Maynard KA. Healing Communities in Conflict: International Assistance in Complex Emergencies. New York: Columbia University Press, 1999

8 WHO. Mental Health Assistance to the Populations Affected by the Tsunami in Asia [www.who.int/mental_health/resources/tsunami/en/] 
9 WHO. Tsunami Wreaks Mental Health Havoc. 1 June 2005 [www.who.int/bulletin/volumes/83/6/infocus0605/en/]

10 Ministry of Health, Republic of Maldives. Maldives National Report for ICMH Expert Review Meeting on Public Health Impact of the Tsunami. Geneva: ICMH, 2005

11 ADRA. Tsunami Response Rep No. 34. 16 May 2005

12 Office for the Coordination of Humanitarian Affairs. Indonesia, Maldives, Sri Lanka, Thailand: earthquake and Tsunami. OCHA Situation Report No. 22, 28 Jan 2005 [www.undp.org/bcpr/disred/ documents/tsunami/ocha/sitrep22.pdf]

13 Isarabhakdi P. Interim Report of a Meeting on Public Health Impact of the Tsunami. Geneva: International Centre for Migration and Health, 2005

14 Hidayat M, Strokoe P. Interim report of a Meeting on the Public Health Impact of the Tsunami. Geneva: ICMH, 2005:7

15 Fullilove MT. Psychiatric implications of displacement: contributions from the psychology of place. Am J Psychiatry 1996;153:1516-23

16 Fullilove MT. Root Shock: How Tearing $U_{p}$ City Neighborhoods Hurts America, and What We Can Do About It. New York: Ballatine, 2004

17 Marzo D. Why not me? Dealing with survivor guilt in the aftermath of a disaster. Selfhelp Magazine 2001 [www.selfhelpmagazine.com/ articles/trauma/guilt.html]

18 Lubit R. Acute treatment of disaster survivors. eMedicine 2005 [www.emedicine.com/med/topic3540.htm]

19 Nath L. India National Report for ICMH Expert Review Meeting on Public Health Impact of the Tsunami. Geneva: ICMH, 2005

20 Maclean K. The impact of institutionalization on child development. Devel Psychopathol 2003;15:853-84

21 Miller L, Chan W, Comfort K, Tirella L. Health of children adopted from Guatemala: comparison of orphanage and foster care. Pediatrics 2005;115:710-17
22 Wolff PH, Fesseha G. Orphans of Eritrea: are orphanages part of the problem or part of the solution? Am J Psychiatry 1998;155:1319-24

23 Nielsen A, Coleman PK, Guimm M, Robb C. Length of institutionalization, contact with relatives and previous hospitalizations as predictors of social and emotional behavior in young Ugandan orphans. Childhood 2004;11:94-116

24 Carballo M, Dzidowska M. Notes on implications of complexemergencies for the elderly (in press)

25 Beller GA. Where high-tech medicine was irrelevant. J Nucl Cardiol 2005; 12:143-4

26 Center of Disease Surveillance and Health Relief After the Tsunami Disaster, Thailand, data as of March 31, 2005

27 Woersching JC, Snyder AE. Earthquakes in El Salvador: a descriptive study of health concerns in a rural community and the clinical implications: part III-Mental health and psychosocial effects. Disaster Manag Response 2004;2:40-5

28 Perera MALR. Sri Lanka National Report for ICMH Expert Review Meeting on Public Health Impact of the Tsunami. Geneva: ICMH, 2005

29 Almedom AM. Factors that mitigate war-induced anxiety and mental distress. J Biosoc Sci 2004;36:445-61

30 Fallot RD, Heckman JP. Religious/spiritual coping among women trauma survivors with mental health and substance use disorders. J Behav Health Serv Res 2005;32:215-26

31 Ano GG, Vasconcelles EB. Religious coping and psychological adjustment to stress: a meta-analysis. J Clin Psychol 2005;61:461-80

32 Bracken PJ, Giller JE, Summerfield D. Psychological responses to war and atrocity: the limitations of current concepts. Soc Sci Med 1005;40:1073-82

33 Chatterjee P. Mental health care for India's Tsunami survivors. Lancet 2005;365:833-4

34 Silove D, Zwi AB. Translating compassion into psychosocial aid after the Tsunami. Lancet 2005;365:269-71 